\title{
Early Identification of Risk Factors for Primary Postpartum Hemorrhage at Admission
}

\author{
Doaa Maged Khalf ${ }^{1}$, Hoda Abd El-Aziam Mohmed² ${ }^{2}$ Abdelrahman Hegazy Abdelwahab $^{3}$
}

(1) Bachelor of Nursing, Faculty of Nursing, Minia University

(2) Professor of Women Health and Obstetric Nursing, Faculty of Nursing, Minia University

(3) Lecturer of Obstetrics and Gynecological Faculty of Medicine, Minia University

\begin{abstract}
Background: Postpartum hemorrhage (PPH) is the world's leading cause of maternal mortality, accounting for onethird of all maternal deaths worldwide. Aim of the Study was early identification of risk factors of primary postpartum hemorrhage. Research Design: A descriptive cross-sectional research design was utilized. Subject and setting: The study was carried out over a period of six months in obstetrics and gynecology department at Minia University Hospital for Obstetric and Pediatric. Tools for Data Collection: two tools were used; Tool I: Sociodemographic characteristics, and Tool II: Risk factors assessment tools. Results: The study revealed that, study group had low risk factors of current PPH had(previous uterine incision, History of PPH ), moderate risk factors of current PPH in women had (prior cesarean birth or prior uterine incision, History of one previous PP), high risk factors of current PPH in women ( had two or more moderate symptoms of risk factors, platelets level $<100,000 / \mathrm{mm}^{3}$, hematocrit level $<30$, placenta previa and suspected placenta accretes) with statistically significance differences. Conclusion: previous uterine incision, previous PPH, abnormality in platelet level, hematocrit level and coagulopathy were the most significant risk factors for primary PPH. Recommendation: Encourage regular antenatal visit to early detection of risk factors of PPH, and providing the women health education about PPH risk factors.
\end{abstract}

Keywords: Postpartum, Pregnant women, Primary postpartum hemorrhage, Risk factors

\section{Introduction}

Postpartum hemorrhage ( $\mathrm{PPH})$ is the world's leading cause of maternal mortality, accounting for one-third of all maternal deaths worldwide. PPH causes up to $60 \%$ of all maternal deaths in developing countries. The majority of these deaths occur within 4 hours of delivery, indicating they are a consequence of events in the third stage of labor (Murakami et al., 2015).

Postpartum hemorrhage remains an important cause of premature mortality of women worldwide; an estimated 500,000 women die from this cause every year with up to of quarter deaths occur due to hemorrhage. Post-Partum hemorrhage may occur in $1-5 \%$ of deliveries in developed as well as in developing countries and it is still most common cause of maternal morbidity and mortality (Gul \& Jabeen, 2018).

Postpartum hemorrhage is an obstetrical emergency that takes place following cesarean or vaginal delivery. Prevention can be achieved through timely diagnosis, provision of essential resources and equipment, and correct management of the third stage of labor. PPH can be classified into two categories: primary and secondary PPH. Primary PPH (early PPH) takes place within the first 24 hours following delivery, whereas secondary or delayed $\mathrm{PPH}$ transpires after 24 hours to 12 weeks following delivery (Jabbar, Perveen \& Kumari, 2019).

Risk factors for postpartum hemorrhage include a prolonged third stage of labor, multiple delivery, episiotomy, fetal macrosomia, and history of postpartum hemorrhage. However, postpartum hemorrhage also occurs in women with no risk factors, so physicians must be prepared to manage this condition at every delivery. Strategies for minimizing the effects of postpartum hemorrhage include identifying and correcting anemia before delivery, being aware of the mother's beliefs about blood transfusions, and eliminating routine episiotomy.
Reexamination of the patient's vital signs and vaginal flow before leaving the delivery area may help detect slow, steady bleeding (Ononge et al., 2016).

Early assessment and aggressive treatment of $\mathrm{PPH}$ are important for reducing morbidity and mortality rates. A critical first step in managing persistent $\mathrm{PPH}$ is rapid recognition that clinically significant bleeding (unresponsive to initial measures) has occurred, with effective communication of the situation to the appropriate team members, both clinical and laboratory staff. Subsequent measures include immediate resuscitation with definitive action to arrest the bleeding (obstetric, surgical, and/or hematologic) and ongoing assessment and monitoring of the response to treatment. Persistent severe $\mathrm{PPH}$ requires early involvement of the most experienced members of the team (Nyflot et al., 2017).

Nursing care during postpartum period is multifaceted requiring knowledge of normal physiologic process as well as potential risks. Anticipatory guidance during postpartum period can have a significant impact on postnatal outcomes. So, the nurse must work toward providing care and education that facilitate holistic family wellness. As well as complete assessment and obstetric history are very important, this might include medical history as; history of medical disease, routine medications and allergies, obstetric history as; gravid, parity, history of postpartum hemorrhage, history of complications during pregnancy, time and mode of delivery, presence of tears or lacerations during delivery, and anesthesia or medications, infant status as; breast or bottle feeding (Downey, Kruse, \& Plonczynski, 2019).

\section{Significance of the study}

According to the study done by Mohamed, (2018) who investigated the maternity outcome of primary postpartum hemorrhage case in El-Minia maternity Hospital 20162017: 2 years study reported that the incidence of primary postpartum hemorrhage (PPH) was $1.88 \%$ in 2016 and 189 
cases $(1.69 \%)$ in 2017 in El-Minia University Maternity Hospital.( Mohamed, 2018).

Postpartum hemorrhage (PPH) is a major cause of maternal mortality and severe morbidity all over the world. The World Health Organization (WHO) estimates that, $\mathrm{PPH}$ is a cause of approximately $25 \%$ of maternal deaths recently; the industrialized countries have witnessed a slow but steady escalation in the incidence of PPH. Developing countries experience a much higher burden of $\mathrm{PPH}$; it is also a momentous cause of maternal death in the developed world. Death from PPH occurs in about 1 per 1000 deliveries in lowresource countries compared with 1 per 100,000 deliveries in high-resource countries. Globally, PPH causes 44,000 to 86,000 deaths per year considering it the leading cause of death in pregnancy (EI Badawy, et al., 2017).

Early identifying maternal risks for postpartum hemorrhage is still an important and useful key point in daily practice because a high risk pregnancy can then be closely monitored by a special team to modify their risk factors. As a result, this may lead to a reduction of maternal morbidity and mortality (Lertbunnaphong, et al., 2010).

\section{Aim of the study}

Early identification of risk factors for primary postpartum hemorrhages and measure the association between these factors and the occurrence of primary PPH at admission.

\section{Research Question}

- What are the levels of women risk factors for primary postpartum hemorrhage at admission?

\section{Subjects and Methods \\ Research Design}

A descriptive cross-sectional research design was utilized to fulfill the aim of this study.

\section{Research setting}

This study was conducted at Minia university hospital for maternity and child at antenatal care department, delivery room and immediate post-partum room.

\section{Subjects:}

The target population included all women in last trimester of pregnancy were admitted to hospital for vaginal or cesarean section (CS) delivery during a period of six month.

Sample included two groups study group who are at risk of PPH, which control group not suffer from $\mathrm{PPH}$ during labor.

\section{Inclusion Criteria:}

- Females showing the clinical diagnosis of primary $\mathrm{PPH}$.

- $\quad$ Age (20:45 years)

- Females who were admitted to antenatal unit at MUHOP.

- Women have blood loss $500 \mathrm{ml}$ or more for vaginal delivery, $1000 \mathrm{ml}$ or more for cesarean section.

\section{Exclusion Criteria:}

- Prenatal chronic disease.

- Females with pregnancy induced diseases (gestational diabetes and preeclampsia and those taking anti-coagulant drugs during pregnancy).
- Women were diagnosed with secondary PPH.

- Preterm labor and gestational age less than 36 weeks.

- Home delivery.

\section{Control group:}

Females who were admitted to hospital for vaginal or cesarean section delivery in last trimester of pregnancy of any age and parity and not suffered from primary $\mathrm{PPH}$ during labor.

\section{Tools of the study}

To achieve the goal of the study, data was collected through using the following

Tools:

Tool I: Socio-demographic characteristics including (age, residence, educational level, occupation and income).

Tool II: Risk factors assessment tool designed by (The Association of Women's Health, Obstetric and Neonatal Nurses, 2015.) to determine level of risk factor of primary postpartum hemorrhage at admission for PPH divided into three parts, to assess low risk factors (5) included (no previous uterine incision, singleton pregnancy, $\leq 4$ - previous vaginal births,,,etc.) moderate risk factor (11) included (induction of labor (with oxytocin) or cervical ripening, multiple gestation, $>4$ - previous vaginal births, prior cesarean birth or prior uterine incision, large uterine fibroids, history of one previous PP.. etc) and high-risk factors (8) included (Active bleeding more than "bloody show, has 2 or more moderate symptoms of risk factor, suspected placenta accrete or percreta, Known coagulopathy, History of more than one previous $\mathrm{PPH}$, ,etc.) (The Association of Women's Health, Obstetric and Neonatal Nurses, 2015).

\section{Procedure:}

An official letter was requested from the Dean of the faculty of Nursing at Minia University to director of Minia university hospital for maternity and child, asking for permission to collect data. Meeting with selected hospital manager to explain the objectives and aim of the study who helped to gain their cooperation and to allow interviewing women during minimal workload activities.

The investigator was attending to selected hospital to collect the data from 9.00 AM to 1.00 PM in two days each week (Sunday and Monday) for six months. The investigator was collected data from antenatal care department, delivery room and immediate post-partum room for six months. The investigator was collect data from 3-6 women each week.

All women were informed that their participation is voluntary and reassurance was given to the women about the confidentiality of their responses. The investigator explained the aim and nature of study briefly through direct personal communication that it was take time from 40-50 minutes with the participants. Oral consent was obtained from the participants before inclusion in the study.

After that the investigator was distribute all questionnaires to women who participated in the study and asked them to fulfill them and the investigator spend this time with women during fulfilling the questionnaires. The investigator was reminding women to answer all questions that present in questionnaires. Duration of data collection was started from middle July 2019 to the middle of December 2019. At the end of data collection the investigator gave 
women advices and instructions about risk factor for primary post-partum hemorrhage.

\section{Validity and Reliability}

To establish validity, The questionnaire was be piloted on panel of five experts in the field of obstetric and gynecological staff and Nursing professors who reviewed the instruments for clarity, relevance, comprehensive understanding ,applicability and easiness ,To establish reliability, statistically done alpha Cronbach way to check the stability of the internal consistency of instrument was 0.651

\section{Ethical consideration:}

A written initial approval was obtained from the dean of the faculty of nursing and from the research ethical committee of the faculty of nursing, Minia University, and approval to conduct the study was obtained from the dean of the faculty of nursing, Minia University.

Oral informed consent was obtained from women who participated in this study after explaining the nature and purpose of the study. Participants were informed that their participation in the study was completely voluntary and acceptance of participants was obtained.
Pilot study:

It was carried out on $10 \%$ of the total study sample (10 women). It was clarity of the tools, assessment of feasibility of fieldwork $\&$ to detect any possible obstacles that might face the investigator with interfere with data collection. Necessary modifications were done based on contents for more simplicity, and clarity. The subjects were included to the actual sample.

\section{Statistical design}

Data entry was done using compatible personal computer. Statistical analysis done by using statistical package of social science (SPSS, IBM version 25) and excel for figures. The content of each tool was analyzed, categorized and then coded. Data were presented using descriptive statistics in the form of frequencies and percentages for qualitative variables, and means and standard deviations for quantitative variables. Statistical significance used at $\mathrm{P}$ value $<0.05$. Odd's Ratio (OR) and their $95 \%$ confidence intervals $(95 \% \mathrm{CI})$ were calculated to compare risk factors for PPH in both groups.

\section{Results}

Table (1): Distribution of the study sample regarding their socio-demographic characteristics $(\mathbf{n}=120)$.

\begin{tabular}{|c|c|c|c|c|c|c|}
\hline \multirow{2}{*}{$\begin{array}{l}\text { Socio-demographic } \\
\text { characteristics }\end{array}$} & \multicolumn{2}{|c|}{$\begin{array}{l}\text { Study group } \\
(\mathrm{n}=60)\end{array}$} & \multicolumn{2}{|c|}{$\begin{array}{c}\text { Control group } \\
(n=60)\end{array}$} & \multicolumn{2}{|c|}{ Test of significance } \\
\hline & No. & $\%$ & No. & $\%$ & $X^{2}$ & $P$ - value \\
\hline \multicolumn{7}{|l|}{ Age / years } \\
\hline Less than 25 & 13 & 21.7 & 13 & 21.7 & \multirow{4}{*}{1.100} & \multirow{4}{*}{.777} \\
\hline $25-30$ & 10 & 16.7 & 11 & 18.3 & & \\
\hline $31-35$ & 26 & 43.3 & 29 & 48.3 & & \\
\hline More than 35 & 11 & 18.3 & 7 & 11.7 & & \\
\hline Mean \pm SD & \multicolumn{2}{|c|}{$25.9 \pm 14.1$} & \multicolumn{2}{|c|}{$25.4 \pm 13.8$} & & \\
\hline \multicolumn{7}{|l|}{ Residence } \\
\hline Urban & 33 & 55.0 & 35 & 58.3 & \multirow[t]{2}{*}{2.136} & \multirow[t]{2}{*}{.144} \\
\hline Rural & 27 & 45.0 & 25 & 41.7 & & \\
\hline \multicolumn{7}{|l|}{ Educational level } \\
\hline Illiterate & 19 & 31.7 & 11 & 18.3 & \multirow{4}{*}{6.133} & \multirow{4}{*}{.105} \\
\hline Basic education & 16 & 26.7 & 12 & 20.0 & & \\
\hline Secondary & 10 & 16.7 & 10 & 16.7 & & \\
\hline University education & 15 & 25.0 & 27 & 45.0 & & \\
\hline \multicolumn{7}{|l|}{ Occupation } \\
\hline Worker & 14 & 23.3 & 20 & 33.3 & \multirow[t]{2}{*}{1.477} & \multirow[t]{2}{*}{.224} \\
\hline House wife & 46 & 76.7 & 40 & 66.7 & & \\
\hline \multicolumn{7}{|l|}{ Income } \\
\hline Low & 49 & 81.7 & 41 & 68.3 & \multirow[t]{2}{*}{2.844} & \multirow[t]{2}{*}{.092} \\
\hline High & 11 & 18.3 & 19 & 31.7 & & \\
\hline
\end{tabular}

Table 1: shows that, $43.3 \%$ of study group and $48.3 \%$ of control group aged between $31-35$ years with mean age $25.9 \pm$ 14.1 and $25.4 \pm 13.8$ years respectively.

Regarding residence, $55.0 \%$ of study group and $58.3 \%$ of control group lived in urban area, $26.7 \%$ of study group and $20.0 \%$ of control group have basic education level.

Concerning occupation, $76.7 \%$ of study group and $66.7 \%$ of control group were housewives and $81.7 \%$ vs 68.3 of them had low income level respectively.

There were no statistically significance differences between study and control groups regarding their socio-demographic characteristics 
Minia Scientific Nursing Journal (Print - ISSN 2537-012X) (Online - ISSN 2785-9797) Vol. (8) No. (1) December 2020

Table (2): Distribution of the study sample regarding their low risk factors of primary post-partum hemorrhage $(\mathrm{n}=120)$

\begin{tabular}{|c|c|c|c|c|c|c|}
\hline \multirow{2}{*}{ Low risk factors } & \multicolumn{2}{|c|}{ Study group } & \multicolumn{2}{|c|}{ Control group } & \multicolumn{2}{|c|}{ Test of significance } \\
\hline & No. & $\%$ & No. & $\%$ & OR $(95 \% C I)$ & $P$ - value \\
\hline \multicolumn{7}{|l|}{ No previous uterine incision } \\
\hline Yes & 12 & 20.0 & 38 & 63.3 & \multirow[t]{2}{*}{$.145(.064-.329)$} & \multirow[t]{2}{*}{$.0001 * *$} \\
\hline No & 48 & 80.0 & 22 & 36.7 & & \\
\hline \multicolumn{7}{|l|}{ Singleton pregnancy } \\
\hline Yes & 53 & 88.3 & 56 & 93.3 & \multirow[t]{2}{*}{$.541(.150-1.954)$} & \multirow[t]{2}{*}{.343} \\
\hline No & 7 & 11.7 & 4 & 6.7 & & \\
\hline \multicolumn{7}{|c|}{ Less than or equal 4- Previous vaginal births } \\
\hline Yes & 24 & 40.0 & 27 & 45.0 & \multirow[t]{2}{*}{$.581(.150-1.954)$} & \multirow[t]{2}{*}{.657} \\
\hline No & 36 & 60.0 & 33 & 55.0 & & \\
\hline \multicolumn{7}{|l|}{ No History of PPH } \\
\hline Yes & 42 & 70.0 & 55 & 91.7 & \multirow[t]{2}{*}{$1.107(.034-.334)$} & \multirow[t]{2}{*}{$.02 *$} \\
\hline No & 18 & 30.0 & 5 & 8.3 & & \\
\hline \multicolumn{7}{|l|}{ Not known bleeding disorder } \\
\hline Yes & 38 & 63.3 & 56 & 93.3 & \multirow[t]{2}{*}{$.123(.039-.387)$} & \multirow[t]{2}{*}{$.0001 * *$} \\
\hline No & 22 & 36.7 & 4 & 6.7 & & \\
\hline
\end{tabular}

Table (2): presents that, study group had low risk for current PPH in previous uterine incision, and known bleeding disorder by less than one folds $(\mathrm{OR}=.145$, and .123 respectively) and history of $\mathrm{PPH}$ by more than one folds $(\mathrm{OR}=1.107)$ with statistically significance differences with $P$ - value $\leq .0001, .0001$, and .02 respectively.

Table (3): Distribution of the study sample regarding their moderate factors of primary post-partum hemorrhage among study sample $(n=120)$.

\begin{tabular}{|c|c|c|c|c|c|c|}
\hline \multirow{2}{*}{ Moderate risk factors } & \multicolumn{2}{|c|}{ Study group } & \multicolumn{2}{|c|}{ Control group } & \multicolumn{2}{|c|}{ Test of significance } \\
\hline & No. & $\%$ & No. & $\%$ & OR $(95 \% C I)$ & $P$-value \\
\hline \multicolumn{7}{|l|}{ Induction of labor } \\
\hline Yes & 34 & 56.7 & 16 & 26.7 & \multirow[t]{2}{*}{$.179(.082-.395)$} & \multirow[t]{2}{*}{$.0001 * *$} \\
\hline No & 26 & 43.3 & 44 & 73.3 & & \\
\hline \multicolumn{7}{|l|}{ Multiple gestation } \\
\hline Yes & 9 & 15.0 & 1 & 1.7 & \multirow{2}{*}{$\begin{array}{l}10.412(1.275- \\
84.998)\end{array}$} & \multirow[t]{2}{*}{$.008^{* *}$} \\
\hline No & 51 & 85.0 & 59 & 98.3 & & \\
\hline \multicolumn{7}{|l|}{ More than 4 - previous vaginal births } \\
\hline Yes & 36 & 60.0 & 33 & 55.0 & \multirow{2}{*}{$\begin{array}{c}.581(.150- \\
1.954) \\
\end{array}$} & \multirow[t]{2}{*}{.657} \\
\hline No & 24 & 40.0 & 27 & 45.0 & & \\
\hline \multicolumn{7}{|l|}{ Prior cesarean birth or prior uterine incision } \\
\hline Yes & 43 & 71.7 & 20 & 38.3 & \multirow{2}{*}{$\begin{array}{c}7.231(3.198- \\
16.347) \\
\end{array}$} & \multirow[t]{2}{*}{$.0001 * *$} \\
\hline No & 17 & 28.3 & 40 & 61.7 & & \\
\hline \multicolumn{7}{|l|}{ Large uterine fibroids } \\
\hline Yes & 15 & 25.0 & 2 & 3.3 & \multirow{2}{*}{$\begin{array}{l}9.667(2.102- \\
44.460)\end{array}$} & \multirow[t]{2}{*}{$.001 * *$} \\
\hline No & 45 & 75.0 & 58 & 96.7 & & \\
\hline \multicolumn{7}{|l|}{ History of one previous PPH } \\
\hline Yes & 8 & 13.3 & 3 & 5.0 & \multirow{2}{*}{$\begin{array}{c}1.247(.140- \\
1.954)\end{array}$} & \multirow[t]{2}{*}{$.05^{*}$} \\
\hline No & 52 & 86.7 & 57 & 95.0 & & \\
\hline \multicolumn{7}{|c|}{$\begin{array}{l}\text { Family history in first degree relatives who experienced } \\
\text { PPH }\end{array}$} \\
\hline Yes & 5 & 8.3 & 7 & 11.7 & \multirow{2}{*}{$\begin{array}{c}.821(.425- \\
1.828) \\
\end{array}$} & \multirow[t]{2}{*}{.845} \\
\hline No & 55 & 91.7 & 53 & 88.3 & & \\
\hline \multicolumn{7}{|l|}{ Chorioamnionitis } \\
\hline Yes & 16 & 56.7 & 5 & 8.3 & \multirow{2}{*}{$\begin{array}{c}4.0(1.359- \\
11.774)\end{array}$} & \multirow[t]{2}{*}{$.008^{* *}$} \\
\hline No & 44 & 73.3 & 55 & 91.7 & & \\
\hline Estimated fetal weight greater than $4 \mathrm{~kg}$ & & & & & & \\
\hline Yes & 10 & 16.7 & 3 & 5.0 & $2.20(2.012-$ & $.032 *$ \\
\hline No & 50 & 83.3 & 57 & 95.0 & 7.214) & \\
\hline Morbid obesity (body mass index [BMI] & & & & & & \\
\hline Yes & 25 & 41.7 & 19 & 31.7 & $2.347(1.067-$ & $.032 *$ \\
\hline No & 35 & 58.3 & 41 & 68.3 & $5.162)$ & \\
\hline Polyhydramnios & & & & & & \\
\hline Yes & 36 & 60.0 & 10 & 16.7 & $7.500(3.196-$ & $.0001 * *$ \\
\hline No & 24 & 40.0 & 50 & 83.3 & 17.601) & \\
\hline
\end{tabular}

**significant at $P$ value $<0.01$

*significant at $P$ value $<0.05$

Table (3): shows that, study group had moderate risk for current PPH in multiple gestation by more than ten folds (OR= 10.412), large uterine fibroids by more than nine folds $(\mathrm{OR}=9.667)$, prior cesarean birth or prior uterine incision, polyhydramnios by more than seven folds $(\mathrm{OR}=7.231 \& 7.500$ respectively $)$, and chorioamnionitis by four folds $(\mathrm{OR}=4.0)$ with statistically significance differences. 
Minia Scientific Nursing Journal (Print - ISSN 2537-012X) (Online - ISSN 2785-9797) Vol. (8) No. (1) December 2020

Table (4): Distribution of the study sample regarding their high factors of primary post-partum hemorrhage among study sample $(\mathbf{n}=\mathbf{1 2 0})$.

\begin{tabular}{|c|c|c|c|c|c|c|}
\hline \multirow{2}{*}{ High risk factors } & \multicolumn{2}{|c|}{ Study group } & \multicolumn{2}{|c|}{ Control group } & \multicolumn{2}{|c|}{ Test of significance } \\
\hline & No. & $\%$ & No. & $\%$ & OR $(95 \% C I)$ & $P$-value \\
\hline \multicolumn{7}{|l|}{ Active bleeding more than "bloody show" } \\
\hline Yes & 7 & 11.7 & 2 & 3.3 & \multirow{2}{*}{$\begin{array}{c}3.830(.762- \\
19.258) \\
\end{array}$} & \multirow[t]{2}{*}{$.05^{*}$} \\
\hline No & 53 & 88.3 & 58 & 96.7 & & \\
\hline \multicolumn{7}{|c|}{ Has 2 or More moderate symptoms of risk factors } \\
\hline Yes & 56 & 93.3 & 4 & 6.7 & \multirow{2}{*}{$\begin{array}{c}196(46.692- \\
822.757) \\
\end{array}$} & \multirow[t]{2}{*}{$.0001 * *$} \\
\hline No & 4 & 6.7 & 56 & 93.3 & & \\
\hline \multicolumn{7}{|l|}{ Suspected placenta accretes or percreta } \\
\hline Yes & 21 & 35.0 & 3 & 5.0 & \multirow{2}{*}{$\begin{array}{c}10.231(2.855- \\
36.666)\end{array}$} & \multirow{2}{*}{$.0001^{* *}$} \\
\hline No & 39 & 65.0 & 57 & 95.0 & & \\
\hline \multicolumn{7}{|l|}{ Known coagulopathy } \\
\hline Yes & 8 & 13.3 & 2 & 3.3 & \multirow{2}{*}{$\begin{array}{c}4.462(.906- \\
21.967) \\
\end{array}$} & \multirow[t]{2}{*}{$.05^{*}$} \\
\hline No & 52 & 86.7 & 58 & 96.7 & & \\
\hline \multicolumn{7}{|l|}{ History of more than one previous PPH } \\
\hline Yes & 10 & 16.7 & 2 & 3.3 & \multirow{2}{*}{$\begin{array}{c}2.636(.491- \\
14.157)\end{array}$} & \multirow[t]{2}{*}{$.05^{*}$} \\
\hline No & 50 & 83.3 & 58 & 96.7 & & \\
\hline \multicolumn{7}{|l|}{ Hematocrit $<30$ AND other risk factors } \\
\hline Yes & 39 & 65.0 & 5 & 8.3 & \multirow{2}{*}{$\begin{array}{c}20.429(7.091- \\
58.852)\end{array}$} & \multirow[t]{2}{*}{$.0001 * *$} \\
\hline No & 21 & 35.0 & 55 & 91.7 & & \\
\hline \multicolumn{7}{|l|}{ Platelets $<100,000 / \mathrm{mm} 3$} \\
\hline Yes & 40 & 66.7 & 2 & 3.3 & \multirow{2}{*}{$\begin{array}{c}58.000(12.834- \\
262.113)\end{array}$} & \multirow[t]{2}{*}{$.0001 * *$} \\
\hline No & 20 & 33.3 & 58 & 96.7 & & \\
\hline \multicolumn{7}{|l|}{ Placenta previa or low-lying placenta } \\
\hline Yes & 38 & 63.3 & 0 & .0 & \multirow{2}{*}{$\begin{array}{c}11.769(4.391- \\
31.546)\end{array}$} & \multirow[t]{2}{*}{$.0001^{* *}$} \\
\hline No & 22 & 36.7 & 60 & 100.0 & & \\
\hline
\end{tabular}

Table (4): result of presents table show that, study group had high risk for current PPH in women had two or more moderate symptoms of risk factors by more than one hundred folds $(\mathrm{OR}=196)$, platelets $<100,000 / \mathrm{mm}^{3}$ by more than fifty folds $(\mathrm{OR}=$ $58.00)$, hematocrit $<30$ by more than twenty folds $(\mathrm{OR}=20.429)$, placenta previa and suspected placenta accretes by more than ten folds $(\mathrm{OR}=11.769 \& 10.231$ respectively $)$, with statistically significance differences.

\section{Discussion}

Postpartum hemorrhage (PPH) is a major cause of maternal mortality and severe morbidity all over the world. The World Health Organization (WHO) estimates that PPH is a cause of approximately $25 \%$ of maternal deaths (Andrikopoulou \& D'Alton, 2019). This study aimed to early identification of risk factors for primary postpartum hemorrhage.

Regarding the socio-demographic characteristics of the study and control groups, the current study showed that less than half of the study group and control group aged between 31 - 35 years This result comes in the line with (El Badawy, et al., 2017) who studied "assessment of risk factors for primary postpartum hemorrhage at Zagazig university hospitals" and reported that the most of them were in the age group 19-34 years (81.4\% of cases and $66.1 \%$ of controls).

This result comes in to agree with Miller et al., (2017) who studied "postpartum hemorrhage following vaginal delivery: risk factors and maternal outcomes" and reported that less than one-third of the cases and control group their age was in between 27:35 years. These results come to differ with (Gudeta, et al., 2018) who studied "magnitude of post-partum hemorrhage among women who received postpartum care at Bedele hospital southwest, Ethiopia, 2018" and reported that less than half of the studied sample their age were in between 20:24 years.

Regarding distribution of the study sample by their low risk factors of primary post-partum hemorrhage, the current study showed that the study group had a low risk for current PPH in women had a previous uterine incision, more than four previous vaginal birth, and known bleeding disorder with statistically significant differences in which $P$ - value $\leq$ $.0001, .02$, and .0001 respectively.
This result come in the line with (El Badawy et al., 2017) who founded that more than two-thirds of the study group and most of the control group had no history of PPH. This result was confirmed by (Belfort., 2019) who studied "Postpartum hemorrhage: Management approaches requiring laparotomy" and stated that the uterine incision increases the risk of PPH. Also this result comes in the line with (Dionne et al., 2015) who stated that there association between low-risk factors and PPH. This result might be due to pregnant women known they suffered from bleeding disorders will continue antenatal visits to decrease risk factors for any postpartum complications and uterine incision is an unusual cause of postpartum hemorrhage as concluded by Zhang et al., (2020)

Regarding distribution of the study sample by their moderate risk factors of primary post-partum hemorrhage, the current study results showed that study group had a moderate risk for current $\mathrm{PPH}$ as multiple gestations, history of one previous $\mathrm{PPH}$, prior cesarean birth or prior uterine incision fetal weight greater than $4 \mathrm{~kg}$, morbid obesity and polyhydramnios, with statistically significant differences in which $\mathrm{P}$ value $<.008, .05, .0001$ and .0001 Respectively.

This result comes in the line with (El Badawy et al., 2017) who stated that There are many risk factors for primary $\mathrm{PPH}$ as increasing maternal age, previous APH and PPH, macrosomia, maternal anemia, obesity, vaginal delivery, labor induction, delivery trauma, retained placenta, and placenta previa. Maternal anemia, retained placenta, macrosomia, and previous $\mathrm{PPH}$ were the most significant risk factors for primary $\mathrm{PPH}$.

This finding might be labor induction may increase duration of labor which may increase frequency of PPH and retained placenta causes uterine atony by preventing uterine contraction, which compresses the myometrial spiral arteries. 
Retained products may cause delayed PPH by interfering with involution of the placental site. Also, multiple gestation and poly-hydramnios increase uterine atomy by uterine over distension, and there was an evidence suggests that $\mathrm{PPH}$ during cesarean birth is occurring more frequently due to not administration of uterotonic agent after delivery. In additional, pregnant women with uterine fibroids are at increased risk for cesarean delivery, and breech presentation and macrosomic is associated with maternal complications such as emergency cesarean section.

Wetta et al., (2013) explained that identified obesity, anemia and infection (chorioamnionitis) as potential independent risk factors, because of its tocolytic effect, one would expect magnesium sulfate to be associated with an increase in the risk of atony or postpartum hemorrhage.

Regarding Distribution of the study sample by their high factors of primary post-partum hemorrhage among study sample, the present study illustrated that study group had a high risk for current $\mathrm{PPH}$ in women had two or more moderate symptom of risk factors, platelets level $<100,000 / \mathrm{mm}^{3}$ by more than fifty folds, hematocrit level $<30$ by more than twenty folds, placenta previa and suspected placenta accretes by more than ten folds with statistically significant differences.

This result differs from (Nyfløt et al., 2017) who studied " Risk severe PPH, anticoagulant medication, anemia at booking, severe pre-eclampsia or HELLP syndrome, uterine fibromas, multiple pregnancies and assisted reproductive technologies. This finding might be explained by, the placenta previa cause poor myometrial contraction with continue hemorrhage from numerous vessels beneath placental area and if the pregnant women known they suffered from bleeding disorders will continue antenatal visits to decrease risk factors for any postpartum complications.

Sneha et al., (2017) reported that the rate of red cell destruction increases during the first day of puerperium leading to a decreased haematocrit and women given oral iron supplementation during pregnancy have larger red cells. It could be that selective destruction of these larger red cells allied to a transient increase in plasma volume during the early puerperium accounts for the initial fall in haematocrit.

\section{Conclusion \\ Based on the findings of the present study it was concluded that}

Previous PPH, abnormality in platelet, hematocrit and coagulopathy were the most significant high risk factors for primary PPH while the moderate risk for current PPH were multiple gestation, history of one previous $\mathrm{PPH}$, prior cesarean birth or prior uterine incision, and polyhydramnios.

\section{Recommendations}

\section{Based on the results of the present study are:}

- Encourage regular antenatal visit to early detection of risk factors of $\mathrm{PPH}$, and providing the women health education about PPH risk factors.

- Nurses should encourage pregnant women for treatment of some risk factor as anemia and encourage hospital delivery for women at risk of PPH.

\section{References}

(1) Andrikopoulou, M., \& D'Alton, M. E. (2019). Postpartum hemorrhage: early identification challenges. Paper presented at the Seminars in perinatology. Semin Perinatol; 43 (1): 11- 17

(2) Belfort, M. (2019). Postpartum hemorrhage: Management approaches requiring laparotomy. Available at https://www.uptodate.com/contents/postpartum-hemorrhage-managementapproaches-requiring-laparotomy\#topicContent

(3) Dionne, M.-D., Deneux-Tharaux, C., Dupont, C., Basso, O., Rudigoz, R.-C., Bouvier-Colle, M.-H., \& Le Ray, C. (2015). Duration of expulsive efforts and risk of postpartum hemorrhage in nulliparous women: a populationbased study. PloS one, 10(11): 1- 12

(4) Downey, J., Kruse, D., \& Plonczynski, D. J. (2019). Nurses Reduce Epidural-Related Urinary Retention and Postpartum Hemorrhages. Journal of PeriAnesthesia Nursing, 34(1), 206-210.

(5) El Badawy, A. A., Waly, E. H., Zaitoun, N. M., \& Abo-Elwan, Y. (2017). Assessment of risk factors for primary postpartum hemorrhage at Zagazig University Hospital. Z.U.M.J., 23(2).

(6) Frass, K. A. (2015). Postpartum hemorrhage is related to the hemoglobin levels at labor: Observational study. Alexandria Journal of Medicine, 51(4), 333-337.

(7) Gudeta, T., Kebede, D., Nigeria, G., Dow, M., \& Hassen, S. (2018) Magnitude of post-partum hemorrhage among women who received postpartum care at Bedele hospital south west, Ethiopia. J Preg Child Health, 5(396), 2.

(8) Gul, F., \& Jabeen, M. (2018). Frequency, causes and outcome of post partum haemorrhage at liaqat memorial hospital kohat, pakistan. Khyber Medical University Journal, 10(2): $90-94$.

(9) Jabbar, S., Perveen, S., \& Kumari, R. (2019). Secondary Postpartum Haemorrhage: Causes and Management In A Tertiary Care Hospital. Annals of Abbasi Shaheed Hospital \& Karachi Medical \& Dental College, 24(1).

(10) Lertbunnaphong, T., Leetheeragul, J. \& Thitadilok, W. (2010). Risk Factors of Primary Postpartum Hemorrhage in Siriraj Hospital. Siriraj Med J; 62:195-198.

(11) Miller, C. M., Cohn, S., Akdagli, S., Carvalho, B., Blumenfeld, Y. J., \& Butwick, A. J. (2017). Postpartum hemorrhage following vaginal delivery: risk factors and maternal outcomes. Journal of Perinatology, 37(3), 243-248.

(12) Miller, C., Ramachandran, B., Akbar, K., Carvalho, B., \& Butwick, A. J. (2016). The impact of postpartum hemoglobin levels on maternal quality of life after delivery: a prospective exploratory study. Annals of hematology, 95(12), 2049-2055.

(13) -Mohamed, K. (2018). Maternity outcome of primary post-partum hemorrhage case in El-Minia maternity Hospital 2016- 2017: 2 years study. Primary Post-Partum Hemorrhage and Maternity Outcome. 8(2):185-188.

(14) Murakami, M., Kobayashi, T., Kubo, T., Hata, T., Takeda, S., \& Masuzaki, H. (2015). Experience with recombinant activated factor VII for severe post $\square$ partum hemorrhage in Japan, investigated by Perinatology Committee, Japan Society of Obstetrics and Gynecology. Journal of Obstetrics and Gynaecology Research, 41(8), 1161-1168.

(15) Nakagawa, K., Yamada, T., Cho, K., Akaishi, R., Kohgo, Y., \& Hanatani, K. (2016). Independent risk factors for postpartum haemorrhage. Critical Care Obstetrics and Gynecology, 2(2), 10.

(16) Nyfløt, L. T., Sandven, I., Stray-Pedersen, B., Pettersen, S., Al-Zirqi, I, Rosenberg, M., . . . Vangen, S. (2017). Risk factors for severe postpartum hemorrhage: a case-control study. BMC pregnancy and childbirth, 17(1), 17.

(17) Oberg, A. S., Hernandez-Diaz, S., Palmsten, K., Almqvist, C., \& Bateman, B. T. (2014). Patterns of recurrence of postpartum hemorrhage in a large population-based cohort. American journal of obstetrics and gynecology, 210(3), 229. e221-229. e228.

(18) Ononge, S., Mirembe, F., Wandabwa, J., \& Campbell, O. M. (2016) Incidence and risk factors for postpartum hemorrhage in Uganda. Reproductive health, 13(1), 38.

(19) Ramler, P. I., van den Akker, T., Henriquez, D. D., Zwart, J. J., van Roosmalen, J., van Lith, J. M., . . . van Goeverden, R. (2019). Women receiving massive transfusion due to postpartum hemorrhage: A comparison over time between two nationwide cohort studies. Acta obstetricia et gynecologica Scandinavica, 98(6), 795-804.

(20) Sneha K. Girish B. and Manjunath M. (2017). Haematocrit as diagnostic tool for assessing Primary Postpartum haemorrhage. Indian Journal of Clinical Anatomy and Physiology;5(2);210-213.

(21) Wetta L., Szychowski J., Seals S., Mancuso M., Biggio J, Tita A. (2013) Risk factors for uterine atony/ postpartum hemorrhage requiring treatment after vaginal delivery. Am J Obstet Gynecol ; 209 (1): 51.

(22) Zhang Y., Ma N., and Pang X. (2020). Uterine incision dehiscence 3 mo after cesarean section causing massive bleeding: A case report. World J Clin Cases; 6 ; 8 (11): $2392-2398$. 